\title{
The role of patents in biodiversity conservation
}

\begin{abstract}
Patents are involved in the global debates about accessing and sharing the benefits of biological resources. Patents, however, may not be establishing clear property and use rights so that they in practice promote biodiversity destruction and decline. The challenge is to adjust the schemes for patents to suit conservation and sustainable use objectives.
\end{abstract}

\section{Introduction}

Patents together with access and benefit sharing are a critical component of conserving biodiversity. This was acknowledged in the objectives of the United Nations Convention on Biodiversity (CBD) to conserve biodiversity (Art 1) together with the recognition that patents and other forms of intellectual property should support the CBD's objectives (including biodiversity conservation and sustainable use: Art 16(5)), and that incentive measures should promote biodiversity conservation rather than its destruction and decline (Art 11). The access and benefit sharing objectives of the CBD have now been implemented as a private contract model according to the voluntary Bonn Guidelines on Access to Genetic Resources and Fair and Equitable Sharing of the Benefits Arising out of their Utilization.[1] In short, the contract sets out the terms and conditions of access with patents contributing to the calculation of the price of access. The question we must ask is whether the access price properly reflects the true costs of biodiversity conservation, and the role and place of patents in contributing to the price of access. So, why should these be the critical issues?

\section{The economic justification}

As a generalisation, developed market based economies have approached biological diversity conservation as a market failure accepting that a properly functioning competitive economy will not conserve biodiversity. This approach reflects the theory that the benefits of biological diversity conservation accrue to society and cannot be sufficiently captured by those likely to undertake the conservation - the marginal private returns from conservation activities do not correspond with their marginal social returns so favouring biological diversity destruction and decline.[2] The 
solution is to establish biodiversity as an object of transaction by regulating access and benefit sharing (a form of property) so as to allow part of the social value for individual economic activities to be appropriated, thus compensating those likely to undertake the conservation activities, and providing an incentive to undertake future conservation activities.[3] The objective of controlling access and benefit sharing is therefore to establish a market for biological diversity conservation that internalises into a market transaction all the costs of the impacts of biological diversity destruction and decline. The contract is the favoured instrument for putting the regulation into effect because it allows private actors to set the terms and conditions of their transaction that is best suited to their particular circumstances.

\section{The role of patents}

Patents and other forms of intellectual property then take their place and role in delivering a part of the compensation (and incentive) contributing to the marginal private return.[4] This is achieved, at least in theory, by capturing some of the value from innovative, creative and useful applications of the accessed biological resources and returning this as part of the price paid for access and use of the biological resources through the royalty or other benefits (such as access to and transfer of a new technology, and so on). In assessing the role of patents in addressing the broader question of whether contracts are an optimal form of regulation for conserving biological diversity, the question is whether patents can deliver value in addition to other benefits negotiated as part of the price of access, so that the marginal private returns from conservation activities (from all sources) are sufficient to at least correspond with their marginal social returns. Unfortunately, this is not a simple assessment.

At least in theory, the property value established in the biological resources by controlling access through a contract can be distinguished from the value of the potential intellectual property from using that biological resource, so that some of the value of the intellectual property can contribute to the compensation and incentive for biological diversity conservation. At its most simple, property rights over the accessed biological resources deals with the tangible 'biological resources'. Patents meanwhile, relate to the intangible innovation and creativity in products and processes that result from using the biological resource. A patent deals with an 'invention' that is novel, 
not obvious, is industrially useful and described in a way that can be followed by others, and establishes 'exclusive rights' to certain dealings with the 'invention'.[5] These are different economy commodities, one the tangible biological resource and the other the intangible application of that biological resource for an innovative or creative and useful purpose.

This distinction between tangible and intangible may not, however, be so elegant in practice. A modern patent confounds both the right to deal with the biological resource as it is embodied in a tangible form (such as a purified and isolated gene sequence, or a composition per se), and the right to prevent others from using the biological resource in other embodiments (such as the gene sequence in a diagnostic device). In short, the uncertainty arises because past claims (and disclosures in the public domain) to compositions per se may limit the value of future uses of the same or similar compositions, even where those uses are entirely different, because the patent's 'exclusive rights' are attached to the composition per se (according to its definition and description) rather than its many and varied useful application(s). As a consequence, the problems posed by patents is the potential to undermine the value of the accessed biological resource and other in situ biological resources by creating uncertain property and use rights in the tangible accessed materials, and the uses of that material in innovative or creative and useful embodiments, including other innovative or creative and useful embodiments. Resolving this problem rests in the first instance, with imposing higher threshold standards (particularly obviousness) so as to clearly distinguish between different innovations and creations. That is, establishing clear property and use rights. This is not, however, so easy to resolve.

A significant concern is to not in any way limit existing intellectual property laws that might 'scare' potential bio-prospectors and investors through claims to 'watering down' or 'weakening' intellectual property standards. This seems the most likely explanation for maintaining the primacy of intellectual property as nations perceive the immediate needs of investment in biological resource-based product research and development ahead of other policy imperatives, such as the longer term goals and benefits of biological diversity conservation.[6] However, the direct consequence is to place a consideration of the most appropriate patents settings outside the consideration of whether they are contributing to, or undermining, biodiversity 
conservation, rather than integrating these policies to achieve the best biodiversity conservation outcomes.

\section{Conclusions}

We don't know whether the access price properly reflects the true costs of biodiversity conservation, and the role and place of patents in addressing the price of access. It seems very likely that the price of access is already too low, thus accounting for the ongoing record of biodiversity destruction and decline. If we do attempt to tailor patents to promote biodiversity conservation, the challenge in implementing any new patent arrangements will be in adjusting the schemes for patents and other forms of intellectual property to suit conservation and sustainable use objectives. This is an exciting prospect with the bonus of actually promoting biodiversity conservation.

\section{References}

1. See Conference of the Parties to the Convention on Biological Diversity, Report of the Sixth Meeting of the Conference of the Parties to the Convention on Biological Diversity, UNEP/CBD/COP/6/20 (Conference of the Parties to the Convention on Biological Diversity, Montreal, 2002) pp 60-62 and 253269.

2. See, for example, Organisation of Economic Co-operation and Development, Managing the Environment: The Role of Economic Instruments (Organisation of Economic Co-operation and Development, Paris, 1994) pp 73-118.

3. See Janssen, J. Global Environmental Change, 9, 313-321 (1999).

4. See Organisation for Economic Co-operation and Development, Harnessing Markets for Biodiversity: Towards Conservation and Sustainable Use (Organisation of Economic Co-operation and Development, Paris, 2003) pp 18-19 and 109.

5. These are the minimum requirements for World Trade Organisation Members according to the Agreement on Trade Related Aspects of Intellectual Property Rights (1994) 33 ILM 1125, Arts 27, 28 and 29.

6. For an example of this preference in Australia see, for example, Lawson, C. and Pickering, C. Prometheus, 22, 355-377 (2004). 